\title{
ENHANCING TEAM EFFECTIVENESS THROUGH LEADER EMOTIONAL INTELLIGENCE AND KNOWLEDGE SHARING: STRUCTURAL EQUATION MODELING APPROACH
}

\author{
Samia Jamshed ${ }^{a *}$, Mohammad Nazri Mohd Nor ${ }^{a}$, Raida Abu Bakar $^{\mathrm{a}}$ \\ ${ }^{a}$ Faculty of Business and Accountancy, University of Malaya, Malaysia \\ *Corresponding Author Email: samia@siswa.um.edu.my
}

\begin{abstract}
Leader's non-cognitive abilities and knowledge sharing behavior among team members remains a central concern of healthcare teams for the effective team outcomes. As in complex healthcare environment leaders have to confront with contradictory behaviors. Therefore, the research study attempts to address question how exchange of knowledge amongst health professionals who are associated and working in teams enhances the team effectiveness under emotionally competent leadership. Considering the factor; that leader emotional intelligence is a critical proficiency which may influences sharing of knowledge in health care teams, in terms of final outcomes and effectiveness criteria. A cross-sectional study with structural modeling approach by using Smart PLS was employed to examine the mediating effect of knowledge sharing on relationship of leader emotional intelligence and team effectiveness Data were analyzed by means of a self-reported questionnaire from 225 health care professionals who were working with teams. The study findings indicated knowledge sharing within interprofessional health care teams is influenced by leader emotional intelligence. Furthermore, it was shown that leader emotional intelligence and knowledge sharing is positively related to team effectiveness. Mediation analysis revealed that knowledge sharing mediates the relationship between leader emotional intelligence and team effectiveness. In practice, the results of the study provide a valuable starting point for healthcare leadership to educate them on emotional competencies and encourage knowledge sharing as it deemed important for achieving effectiveness.
\end{abstract}

Keywords: Knowledge sharing, Leader Emotional Intelligence, Team effectiveness 


\section{INTRODUCTION}

Team effectiveness (TE) remains a central focus of almost all healthcare reforms aided by diverse knowledge of the health professionals under dynamic leadership. The operational infra-structure of healthcare developments further depends on the discourse of strategy which is reached beyond the extent of basic plans and structural arrangements in teams. The evolving structure of team-based organizations has provoked management scholars, researchers and practitioners to concentrate on factors that lead to positive team performance. Consequently, growing importance of work teams are considered major agents of knowledge sharing (KS) where leaders play flexible role in providing platform for exchange of knowledge.

Thus, in momentary and cross-functional teams, emotional intelligence is pertinent for effectiveness and success of teams (Hong, Catano, \& Liao, 2011). Teamwork to be successful, the team members need to be coordinated (Finn, Currie, \& Martin, 2010; Berlin, 2010); for this team leaders are responsible for the success of the teams they lead. As such, they are not only responsible for their own emotions, but also for the emotions of the team they lead and the clients of the team (Rafaeli \& Worline, 2001). Therefore, to influence and move people, leader must possess the knowledge and skills of emotional competencies (Boyatzis \& Ratti, 2009); because emotional competencies envisaged a leader to understand the depth of the working behaviors of the member.

Management of a team can, however, be based on different ideals and principles (Berlin, Carlström \& Sandberg, 2012). Considering the different nature of task, effective functioning of healthcare team is deemed to be critical factor determining the success or failures that requires significant team's leadership (Thylefors \& Person, 2014). Due to 
increased distortion of the organizational boundaries and the propagation of autonomous work teams, leader's emotional competencies are becoming increasingly important to employees (Hong et al., 2011). In context of service industry the influence of team leaders and teamwork is different from the traditional supervisory and control methods; teamwork is not just about people who do the same job rather spreads throughout the entire organization such as managing workers, look for catering and clerical staff, maintenance and housekeeping issues for the benefit of the clients, hence the importance of collaboration among the staff (Camillo \& Di Petro, 2013).

Management practitioners and researchers emphasize on investigating the skills and techniques needed to achieve team excellence in all sectors of service industry. Among all service industry; healthcare services is the most critical; as their central premise is to provide health treatments to patients suffering from complex diseases. Therefore modern healthcare is delivered by multidisciplinary, distributed healthcare teams who rely on effective teamwork to ensure effective and safe patient care (Weller, Boyd \& Cumin, 2014) and the effectiveness of teams depend on their social interaction within group members. Though studies exist but little is known about the link between the role of leader's emotional intelligence and knowledge sharing of team members and its effectiveness in healthcare teams.

This study attempts to determine whether, and if so, emotional intelligence of the leader and knowledge sharing amongst members enhances team effectiveness. Lazovic (2012) states that commitment to acquiring new knowledge is related to the quality of interpersonal relations and those relations rely to a great extent on emotional intelligence of key individuals. Further Jayasingam, Ansari, Jantan \& Ramayah (2013) in their studies 
identified enablers such as leader behavior and human resource practices that could improve knowledge sharing practices, and subsequently lead towards improved outcomes. Therefore this paper proceeds in light of current literature and given definitions of leader's emotional intelligence, knowledge sharing and team performance specifically in terms of team effectiveness. The following section presents the comprehensive literature review and the development of the research model. The construct operationalization, data collection, data analysis, and model testing results are described in the methodological approach, after which the researcher interpret the findings and discuss implications for research and practice.

\section{AIMS AND PURPOSE}

This article identifies leader emotional intelligence is a critical proficiency for sharing knowledge in health care teams; as the most significant of all, in terms of final outcomes and effectiveness criteria, are the medical and nursing teams (Shetach \& Marcus, 2015). The role of leadership in healthcare environment includes progression of teamwork and positive self- esteem among the members of the clinical team. The findings of the study revealed that an emotionally intelligent leader provides direction that may ensure team members to work collaboratively and provide platform for sharing knowledge that ultimately enhances team effectiveness. Consequently the study confirmed that leader emotional intelligence can nurture the sharing of knowledge and enhance effectiveness of teams working in private hospitals of Pakistan. 


\section{LITERATURE REVIEW}

\section{Deciphering Leadership \& Emotional Intelligence}

Emotional Intelligence (EI) has been found to correlate with service quality (Naeem, Saif \& Khalil, 2011) and deficiency of El can be a cause of psychological stress at work (Rahim, 2010). Scholars have refuted that emotional intelligence leads to high performance (Druskat \& Wheeler, 2001; Schein, 1992). Therefore, the emotional intelligence of leaders can enhance team effectiveness by exercising the assigned authority (Gardner \& Stough, 2002).

Emotional Intelligence (EI) incorporate fundamental competencies that can be ameliorated through actual practice, reflection and feedback. Lunenburg (2011) described that multiple intelligences construct and emotional intelligence established immense consideration, mainly by means of leadership capability. El is pertinent for persons working in leadership positions; as it enable leader to build and refine connections mandatory for successful teamwork (Klare, Behney \& Kenney, 2014). According to Hong, Catano \& Liao (2011, p. 321), leadership is: "an intrinsically emotional process in which leaders display certain emotions and attempt to evoke and control other emotions in their followers".

El enables the leader to become aware of strengths and weaknesses of his firm in addition to capability of his team. Leader El creates emotional realization and sense of responsibility among team members, which enable them to react adaptively to different situations. An emotionally intelligent leader enjoys wide variety of traits: having a clear vision, highly motivated to accomplish tasks, a synthetic view to apprehend an uncertain situation and being self-confident of his abilities (Azouzi, \& Jarboui, 2013). According to 
Clarke (2010, p. 128): "The outcome of this emotional exploration in conjunction with critical reflection leads to greater self-trust, inner strength and feelings of courage. By recognizing the interdependent relations of feelings and critical reflection there are significant implications for transformative learning". People with higher El are more sensible toward their own and others emotions in the workplace, which allows them to adjust their mental status, and to develop positive emotional expressions and self-control on the job (Chen, Bian \& Hou, 2015). Therefore managers with high emotional intelligence are effective leaders who realize organizational goals with maximum productivity, satisfaction, and employee commitment (Raesli, Honarvar, Fallah \& Behnood, 2016).

\section{Knowledge Sharing and Team Effectiveness}

The phenomena of knowledge sharing is imperative in teams and organizations. The foundation of knowledge management is the sharing of knowledge that encourages ability to provide effective outcomes (Huang, 2013). In this article knowledge sharing is being examined as an important factor that has propensity to produce effective team outcomes. As a social behavior knowledge sharing of an individual working in team is inevitably susceptible to various social influences arising from other team members. Specifically, knowledge sharing in work teams refers to team members sharing taskrelevant information, experiences, and perspectives with each other.

Pangil \& Chan (2014) in their study concluded that knowledge sharing is important regardless the team type, as organizations have made increased use of work teams as fundamental units of organizational structure reliant on leadership. According to Moriarty \& Buckley (2003), work teams are defined as "Groups that exist within the context of larger organization, have clearly defined membership and shared responsibility for a team 
project or service". When it comes to team working; effectiveness is a key concern for the members because they own responsibility for the outcomes. Team effectiveness is defined as "process when employees effectively exchange information and resources with, actively collaborate with, and respond to other team members' needs and requests in an appropriate manner" (Farh, Seo, \& Tesluk, 2012, p. 891) and knowledge sharing enables required collaboration.

The attributes of effective teams comprise: healthcare professionals perceptions of the absolute technical quality of care provided, the second ability involves the extent to which they are able to meet family member needs and the third involves the use of strategies to reduce turnover of members in their respective teams. These conditions are merely dependent on the environment and the context of the team working because health-care organizations requires critical team working because of critical and sensitive operational working within departments and units.

\section{RESEARCH MODEL \& HYPOTHESIS DEVELOPMENT}

As discussed earlier that interprofessional teamwork is one of the most important quality criteria for health care organizations (O'Leary, Sehgal, Terrell \& Williams, 2012; Ezziane, Maruthappu, Gawn, Thompson, Athanasiou, \& Warren, 2012) due to the complexity of the health care system and processes with the changing demands in health care call for effective collaboration among different groups and respective health care professionals. Effective teamwork is associated with high team performance of staff as well as excellence in meeting patient family member needs. The staff-related outcomes are contingent on capable leadership that leads to team effectiveness encourages cost savings, tends to retain staff and reduce turnover (Ezziane et al., 2012; O'Leary et al., 
2012). Therefore, for effective functioning of the healthcare teams, it is important that staff turnover should be reduced and team members possess ability to share knowledge and choose the best course of action in shadow of emotionally competent leadership. Team leader encourages team members to embrace change, offer differing viewpoints, and discuss problems openly leading to constructive and positive outcomes. It is therefore relevant to know more about a team's functional leadership in healthcare - in particular, the extent to which doctors, in their role as team leader, encourage, support and coordinate teamwork (Berlin, 2014). Therefore, it is hypothesized as:

\section{H1: Leader emotional intelligence has significant positive relationship with team effectiveness.}

Healthcare leaders are expected to build and sustain productive teams. However, due to organizational changes in health care, nurse leaders' roles have become increasingly managerial and removed from front-line nursing. This may create a climate of distrust between staff and leaders (Udod \& Care 2013). Therefore, due to the ever-changing work scenarios leading with emotional intelligence may be regarded as a means to bridge this gap (Heckemann, Schols \& Halfens, 2015). Leaders equipped with emotional intelligence may anticipate that group member's behavior and encourage them to share norms, behaviors, basic assumptions that would improve their team's effectiveness.

Previous studies have shown that team processes and team performance are rated differently by different professional groups within interprofessional health care teams (Körner, Göritz, \& Bengel, 2014). Whereas physicians tend to evaluate team processes rather positively, other team members, e.g. nurses, are more critical and often evaluate these variables more negatively (Körner et al., 2014). Hence, it can be assumed that the 
differences in the perceptions of teamwork are an indicator for professional silos. This could be due to a lack of knowledge integration and result in bad team performance Therefore, it is hypothesized that the leaders' emotional intelligence influences members to share knowledge that ultimately leads to better team outcomes.

\section{H2: Leader emotional intelligence has significant positive relationship with knowledge sharing}

Earlier research have found positive effects of knowledge sharing on effectiveness of teams (Mesmer-Magnus \& DeChurch, 2009). Developing and promoting a mindset for knowledge exchange within an interprofessional team is very important for accomplishing complex medical tasks. Therefore, the sharing of diverse knowledge of the health professions is a precondition for effective teamwork and team performance (Mesmer-Magnus \& DeChurch, 2009; Xiao, Parker \& Manser, 2013). In this field, the task can only be successfully completed by sharing the knowledge and resources of the different health care professionals within the healthcare team (Steinheider, Bayerl, Menold \& Bromme, 2009).

Hence team performance could be affected by knowledge-sharing (Plowman \& McDonough, 2010); that the KS mechanism varied due to El (Mesmer-Magnus \& DeChurch, 2009) and consequently determinate team performance (DeDreu \& Weingart, 2003). According to the study by Liu \& Liu (2013), leader El promote performance of teams by boosting team member interactions and encourage knowledge sharing between members of the team. Thus, reporting to an emotionally intelligent leader means having access to a relative wealth of various resources (Elfenbein, 2014; Sonenshein, 2014). Therefore to test the mediating role of knowledge sharing it is hypothesize as:- 


\section{H3: Knowledge sharing has significant positive relationship with team effectiveness.}

H4: The relationship between leader emotional intelligence and team effectiveness is mediated by knowledge sharing.

On the basis of the above discussion and hypothesis development Figure 1 presents the theoretical framework for the study.

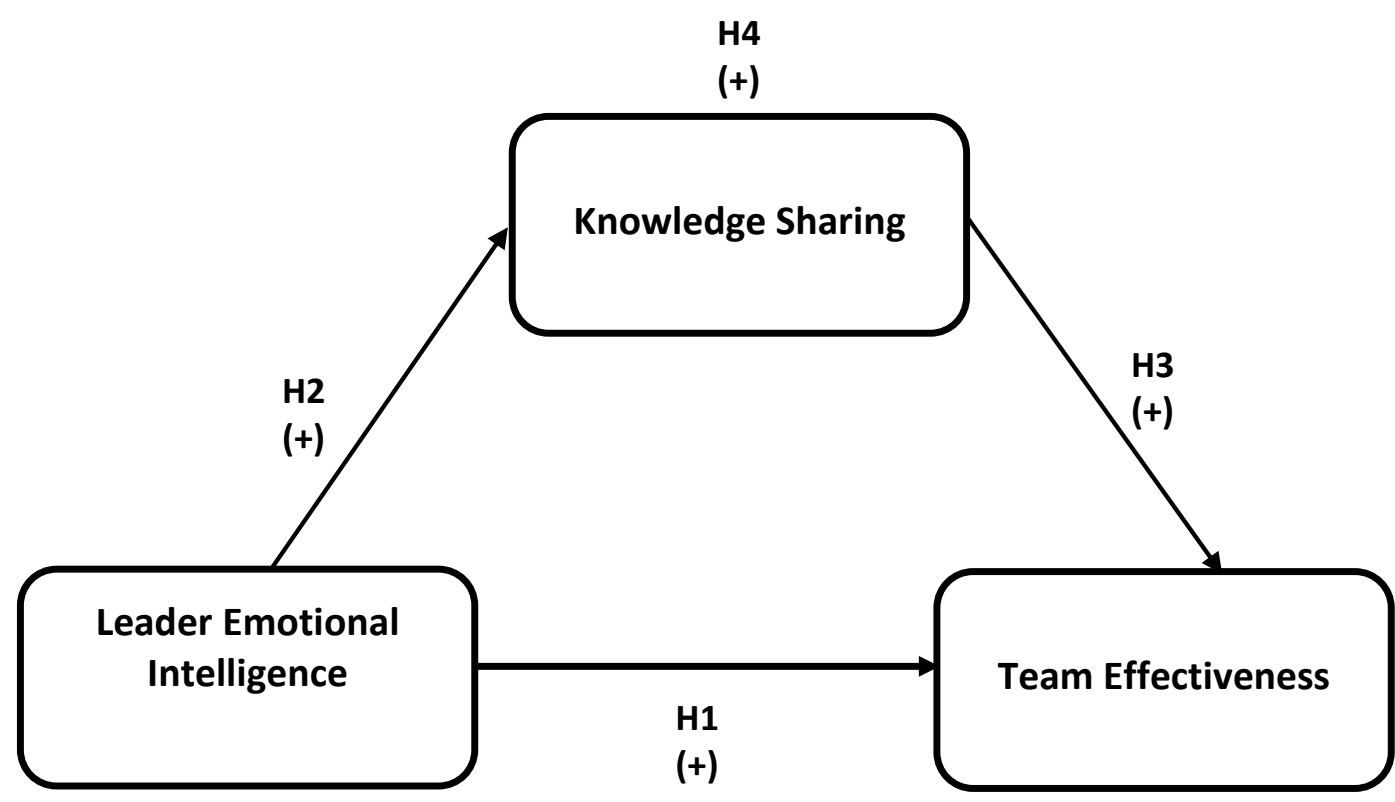

Figure 1. Theoretical framework of Leader emotional intelligence, knowledge sharing, and team effectiveness

\section{METHODOLOGICAL APPROACH}

\section{Procedure}

The population used in study comprised of individuals who are associated with healthcare teams either as team leader or as team member working in health care sector of Pakistan.

The individuals were approached to answer the survey with the permission of the hospital administrators. A total of 380 interprofessional medical professionals that included team leaders and team members were purposefully approached using convenience sampling 
from a largest private sector hospitals. The self-reported surveys were sent to the designated persons appointed by the respective hospital administrators for this task. The designated persons distributed the surveys to health care professionals who were working in interprofessional medical and para medical teams. Out of distributed survey questionnaires ( $n=380$ ) a total of 240 (response rate: 63.2 percent) were returned to the research team. Further 15 surveys were eliminated as they do not fit the criteria of participation in the research leaving behind 225 surveys for full analysis from seven biggest private hospitals of Lahore Pakistan.

Team tenure ranged from 6 months to 60 months $(M=32.28, S D=9.2)$. On the basis of the gender out of total of 225 respondents $63 \%$ (142) of the respondents were males and remaining $37 \%$ (83) were females. The highest percentage i.e. $33 \%$ of the respondents lies in between the category of 26 to 30 years. According to the level of education by 42 $\%$ of the respondents are post graduates. Out of the total respondents 225 are doctors that constitutes $33.1 \%$ and second major respondents are nurses that constitutes $28.8 \%$ $\&$ of the respondents.

\section{Measures}

The survey used validated scales adopted from literature; consisting of total 35 items both positively and negatively phrased. Each variable is measured by multiple items/statements and responses appeared on a 7-point Likert Scale ranging from "strongly disagree" to "strongly agree". Leader emotional intelligence was captured by using Wong and Law emotional scale (Wong \& Law, 2002). This 16 -item scale is based on four dimensions of El; i.e. Self-emotion appraisal ( $\alpha=0.729$ ), others' emotion appraisal 
( $\alpha=0.805)$, utilization of emotions $(\alpha=0.812)$, and regulation of emotions $(\alpha=0.865)$. The knowledge sharing was assessed by using 8 items scale developed by Bartol, Liu, Zeng, $\&$ Wu (2009); which possess $\alpha=0.816$. Lastly the team effectiveness was assessed using 11 items, adopted from Shortell et al (1991) which is widely used for measuring team effectiveness in healthcare teams. It reflects how effectively team members meet family needs and provide quality solutions within team. Tests of reliability (Cronbach alpha was 0.812) demonstrate that each scale is a strong measure of its respective underlying concept.

\section{DATA ANALYSIS}

A structure equation modeling approach in SMART-PLS was employed for data analysis, which is a two stage approach (Chin, 2010). The initial step requires the development and assessment of the measurement model and the later stage requires the development and assessment of the structural model in order to test the extent to which the causal relationships specified by the proposed model are consistent with the available data (Cepeda-Carrión, Cegarra-Navarro \& Jiménez-Jiménez, 2012). Moreover, bootstrapping was applied in order to test hypothesis as recommended by Chin (1998).

\section{RESULTS}

\section{Measurement Model}

The measurement model was assessed to ensure reliability and validity of the constructs. In this research study Leader emotional intelligence (LEI), Knowledge sharing (KS) and Team Effectiveness (TE) are the constructs with specified indicators. 


\section{Convergent Validity}

Convergent validity was measured by assessing (1) factor loading for each indicator and (2) the value of average variance extracted (AVE) for each construct which should be at least 0.50 . Table 1 shows the factor loading for each indicator in the outer model exceeded 0.50 and the value of AVE for each construct is also above 0.50 which is an acceptable threshold value as mentioned by Fornell and Bookstein (1982). Further the weights for each indicator provide information that how each indicator contributes to the respective construct (Chin, 1998). As reported in table 1 the VIF was measured to assess outer model, the values for each construct falls in range $1<\mathrm{VIF}<$. Therefore the maximum VIF Ovalue for the indicators was adequate.

\section{Internal Reliability}

For measuring construct reliability, on recommendations by Chin (1998) and Henseler \& Fassott (2009), this study utilizes composite reliability as a measure of inner consistency. While analyzing results, it was observed that all constructs are reliable as the estimations of cronbach alpha and composite reliability for the each variable is higher than 0.7 which is adequate as indicated by (Hair, Black, Babin, Anderson \& Tatham, 1998) as reported in table 1.

\section{Discriminant Validity}

The discriminant validity was measured according to the Fornell-Larcker criterion (Fornell \& Larcker, 1981), where the value of AVE for each construct should be higher than its highest squared correlation with any other construct. The former assesses discriminant validity on the indicator level, whereas the latter assesses discriminant validity on the 
construct level (Henseler \& Fassott, 2009). This condition is satisfied as reported in Table

2.

Table 1: Assessment of Outer Model

\begin{tabular}{|c|c|c|c|c|c|}
\hline Constructs & VIF & Loading & weight & Composite Reliability & AVE \\
\hline \multicolumn{6}{|l|}{ Leader EI } \\
\hline Self-emotion appraisal & 2.101 & & & 0.832 & 0.554 \\
\hline \multicolumn{6}{|l|}{ (SEA) } \\
\hline SEA1 & & 0.787 & 0.068 & & \\
\hline SEA2 & & 0.736 & 0.106 & & \\
\hline SEA3 & & 0.656 & 0.076 & & \\
\hline SEA4 & & 0.790 & 0.138 & & \\
\hline Other Emotion & 2.019 & & & 0.872 & 0.632 \\
\hline \multicolumn{6}{|l|}{ Appraisal (OEA) } \\
\hline OEA1 & & 0.653 & 0.714 & & \\
\hline OEA2 & & 0.516 & 0.391 & & \\
\hline OEA3 & & 0.617 & 0.361 & & \\
\hline OEA4 & & 0.767 & 0.379 & & \\
\hline Regulation of Emotion & 2.716 & & & 0.908 & 0.712 \\
\hline \multicolumn{6}{|l|}{ (ROE) } \\
\hline ROE1 & & 0.728 & 0.109 & & \\
\hline ROE2 & & 0.784 & 0.168 & & \\
\hline ROE3 & & 0.753 & 0.100 & & \\
\hline ROE4 & & 0.891 & 0.091 & & \\
\hline
\end{tabular}




\begin{tabular}{|c|c|c|c|c|c|}
\hline Utilization of Emotion & 2.866 & & & 0.877 & 0.643 \\
\hline \multicolumn{6}{|l|}{ (UOE) } \\
\hline UOE1 & & 0.856 & 0.103 & & \\
\hline UOE2 & & 0.830 & 0.057 & & \\
\hline UOE3 & & 0.855 & 0.069 & & \\
\hline UOE4 & & 0.648 & 0.070 & & \\
\hline Knowledge sharing & & & & 0.861 & 0.439 \\
\hline KS1 & 1.940 & 0.640 & 0.169 & & \\
\hline KS2 & 1.488 & 0.602 & 0.182 & & \\
\hline KS3 & 2.253 & 0.715 & 0.181 & & \\
\hline KS4 & 1.804 & 0.708 & 0.202 & & \\
\hline KS5 & 1.730 & 0.561 & 0.127 & & \\
\hline KS6 & 1.463 & 0.587 & 0.180 & & \\
\hline KS7 & 1.613 & 0.669 & 0.225 & & \\
\hline KS8 & 2.242 & 0.790 & 0.23 & & \\
\hline Team effectiveness & & & & 0.922 & 0.569 \\
\hline ABTQI & 1.459 & 0.737 & 0.143 & & \\
\hline ABTQ2 & 2.691 & 0.787 & 0.143 & & \\
\hline ABTQ3 & 1.893 & 0.715 & 0.155 & & \\
\hline ABTQ4 & 2.927 & 0.700 & 0.109 & & \\
\hline ABTQ5 & 3.187 & 0.731 & 0.150 & & \\
\hline MFN1 & 1.465 & 0.732 & 0.131 & & \\
\hline MFN2 & 2.144 & 0.748 & 0.205 & & \\
\hline
\end{tabular}




\begin{tabular}{llll} 
TO1 & 2.809 & 0.813 & 0.205 \\
TO2 & 2.762 & 0.772 & 0.129 \\
TO3 & 2.860 & 0.783 & 0.144 \\
TO4 & & & \\
\hline & 2.077 & 0.730 & 0.139
\end{tabular}

Table 2: Discriminant validity

Constructs

Leader EI

Knowledge Sharing

Team Effectiveness
Leader El Knowledge Sharing

\subsection{2}

0.688

0.613
0.766

0.679
Team Effectiveness

Note: The values in bold are the square root of variance shared between the latent variable and all other variables.

\section{Structural Model}

After establishing adequate level of reliability and validity in outer model the second stage in PLS approach is to assess structural model. Structural model is evaluated based on bootstrapping for hypothesis testing, magnitude and significance of the path coefficients, explained variance (value of R2), effect sizes (F2) and test for predicative relevance (Roldán \& Sanchez-Franco, 2012). Table 3 explains the relationship of three direct connections among the variables $\mathrm{LEI}, \mathrm{KS} \& \mathrm{TE}(\mathrm{H} 1, \mathrm{H} 2$, and $\mathrm{H} 3)$ and the one indirect relationship ( $\mathrm{H} 4)$. The first hypothesis proposed the positive relationship between LEI \& KS $(H 1)$ which is significant $(\beta 1=0.226$; $t$-value $=2.093)$. The relationship between LEI \& KS $(H 2)$ is also highly significant $(\beta 2=0.766 ; t$-value $=26.681$. Considering $H 3$ when knowledge sharing was added in the leader emotional intelligence which again explains 
the significant relationship $(\beta 3=505 ; t$-value=5.443). To assess the mediating effect of knowledge sharing between leader emotional intelligence and team effectiveness the indirect path coefficients were examined. On assessing the mediating affect the path coefficient and $\mathrm{T}$ value has increased $(\beta=0.226, \mathrm{~T}=2.093$ to $\beta=0.387, \mathrm{t}-\mathrm{value}=5.520)$. This indicated knowledge sharing mediated the relationship between leader emotional intelligence and team effectiveness hence hypothesis four was supported as well as reported in Table 3.

Table 3: Structural Model

\begin{tabular}{|c|c|c|c|c|c|c|c|}
\hline Relationships & $\begin{array}{c}\text { Original } \\
\text { Sample } \\
\text { (0) }\end{array}$ & $\begin{array}{c}\text { Sample } \\
\text { Mean } \\
\text { (M) }\end{array}$ & $\begin{array}{c}\text { Standard } \\
\text { Deviation } \\
\text { (STDEV) }\end{array}$ & $\begin{array}{c}\text { T Statistics } \\
\text { (|O/STDEV|) }\end{array}$ & P Values & Result & $\mathbf{R 2}$ \\
\hline H1: LEI -> TE & 0.226 & 0.239 & 0.108 & 2.093 & $* 0.037$ & Supported & 0.398 \\
\hline H2: LEI -> KS & 0.766 & 0.771 & 0.0290 & 26.681 & $* * 0.000$ & Supported & 0.509 \\
\hline H3: KS -> TE & 0.505 & 0.500 & 0.093 & 5.443 & $* * 0.000$ & Supported & \\
\hline H4: LEIxKS-> & & & & & & Supported & \\
\hline TE & 0.387 & 0.385 & 0.707 & 5.520 & $* * 0.000$ & & \\
\hline
\end{tabular}

\section{DISCUSSION}

This research study was designed to examine the role of leader emotional intelligence (LEI) and knowledge sharing (KS) towards team effectiveness (TE) in health sector. Health care organizations comprised of multifaceted structure working with medical, paramedical and non para-medical professionals working in different departments and teams. Professionals working in teams may differ in experiences, expectations, values and skills (Reeves, Lewin, Espin \& Zwarenstein, 2011) therefore emotional skills of leaders are of paramount importance with reference to leading healthcare teams. Emotionally intelligent leader tends to understand emotions of team members and create an environment to integrate and share knowledge among team members that contributes 
to overall team effectiveness (TE). In this research study four hypothesis were tested. Initially it examined the relationship of LEI \& TE, as assumed and results indicated that leader emotional intelligence positively influences the performance of the members for effective team functions (Azouzi \& Jarboui, 2013). Further teams with an established relationship of emotional affect, would allow them to process tasks more efficiently, thereby positively affecting team performance (Ghuman, 2016) by sharing knowledge. The results indicated that that better knowledge sharing in teams is associated with better team outcomes. Moreover, the effective functioning of the medical and paramedical team members may be linked with knowledge sharing (KS) and the exchange of task related knowledge leads team effectiveness. The study confirmed a positive effect of knowledge sharing on team effectiveness. This finding is consistent with the results of studies on knowledge sharing and team effectiveness which concluded that team performance could be affected by knowledge-sharing (Plowman \& McDonough, 2010) and knowledge sharing mediates the relationship between leader Emotional intelligence and team effectiveness. Although the investigation of leader emotional intelligence and knowledge sharing and its relation team effectiveness are known to potentially support team effectiveness. These findings could be important for healthcare leadership with respect to provide education of becoming emotionally intelligent. The emotionally competent leader is perhaps the most important element in maintaining harmony in team, enhance knowledge sharing mechanism and to reveal key issues in team effectiveness (Steinheider et al., 2009), as limited research exists in this field. 


\section{LIMITATIONS AND FUTURE DIRECTIONS}

Although the research has met the objectives but limitations of the study are unavoidable.

First the sample of the research was drawn only from the largest private hospitals of Lahore Pakistan which is not generalizable to other healthcare teams that are working in public and trust hospitals that might have produced different results as these sectors have different working structure that may influence the working behaviors of the employees.

Secondly the unit of analysis of the study were individuals who were members of the team; for future study data can be gathered in team and analysis could be perform at the team level which may produce significant results and reveal important factors which can contribute to team effectiveness. In addition, data for the current study was collected via single source that may raise the problem of common method bias. In future studies; data for different variables could be collected from different sources which includes leaders and the members which will address the problem of common method bias.

Lastly it was a cross-sectional study therefore causality links between the variables could not be established. Variables and measures used in the research captured the leader and knowledge sharing behavior of the members and their propensity to produce effective team work. In future studies, the culture and other team processes mechanisms could also be study in relation to team effectiveness of the healthcare teams. However, the study was built on solid theory in light of previous research evidence that leader emotional intelligence influences knowledge sharing behavior of the members for the effective team outcomes. 


\section{PRACTICAL AND THEORETICAL IMPLICATIONS}

The practical implications of the study provide valuable inputs for the team effectiveness.

The healthcare teams confronting with high work demands where leaders emotional intelligence can create support by understanding emotions of the team and can create pool of knowledge by sharing with other health care professionals. This study provide empirical evidence for health care leadership to educate team members on non-cognitive abilities like emotional intelligence skill and encourage them to share knowledge for most effective outcomes by effective utilization of team resources within a team.

This study will enable researchers and leadership professional to understand how knowledge sharing within the team environment is influenced by the emotional skills of the leader in a team. Further it will contribute to the body of knowledge by providing better understanding to designed healthcare reforms in a way that encourages knowledge sharing behavior for the enhanced team outcomes. The challenges of organizing health care in the modern context are considerable due to continual improvements in medical technologies, greater level of knowledge and awareness amongst patient populations. Earlier studies in relation to effective team working have been conducted in developed countries and under developed countries like Pakistan is under researched as stated by Imran, Aftab, Haider \& Farhat (2013). Therefore, to bridge the gap in body of literature this research model examined team effectiveness in relation to leader emotional intelligence and knowledge sharing as a mediator in healthcare sector of Pakistan. 


\section{REFERENCES}

Azouzi, M. A., \& Jarboui, A. (2013). CEO emotional intelligence and board of directors' efficiency. Corporate Governance: The International Journal of Business in Society, 13(4), 365-383.

Bartol, K. M., Liu, W., Zeng, X., \& Wu, K. (2009). Social exchange and knowledge sharing among knowledge workers: The moderating role of perceived job security. Management and Organization Review, 5(2), 223-240.

Berlin, J. M. (2010). Synchronous work - myth or reality? A critical study of teams in health and medical care. Journal of Evaluation in Clinical Practice, 16(6), 1314-1321.

Berlin, J. M., Carlström, E. D., \& Sandberg, H. S. (2012). Models of teamwork: ideal or not? A critical study of theoretical team models. Team Performance Management: An International Journal, 18(5/6), 328-340.

Boyatzis, R. E., \& Ratti, F. (2009). Emotional, social and cognitive intelligence competencies distinguishing effective Italian managers and leaders in a private company and cooperatives. Journal of Management Development, 28(9), 821838.

Camillo, A., \& Di Pietro, L. (2013). Managerial Communication in the Global Cross-Cultural Context. In Cultural and Technological Influences on Global Business (pp. 397419). IGI Global.

Chen, A., Bian, M. and Hou, Y. (2015). Impact of transformational leadership on subordinate's El and work performance. Personnel Review, 44(4), 438-453.

Chin, W. W. (2010). How to write up and report PLS analyses. Handbook of partial least squares, 655-690.

Clarke, N. (2010). Emotional intelligence and learning in teams. Journal of Workplace Learning, 22(3), 125-145. 
Cepeda-Carrión, G., Cegarra-Navarro, J. G., \& Jimenez-Jimenez, D. (2012). The effect of absorptive capacity on innovativeness: context and information systems capability as catalysts. British Journal of Management, 23(1), 110-129.

Chin, W. W. (1998). The partial least squares approach to structural equation modeling. Modern methods for business research, 295(2), 295-336.

De Dreu, C. K., \& Weingart, L. R. (2003). Task versus relationship conflict, team performance, and team member satisfaction: a meta-analysis.

Druskat, V.U. \& Wheeler, J.V. (2001), "Managing from the boundary: the effective leadership of self-managing work teams", paper presented at the Annual Academy of Management Meeting, Washington DC.

Elfenbein, H. A. (2014). The many faces of emotional contagion: An affective process theory of affective linkage. Organizational Psychology Review, 4(4), 326-362.

Ezziane, Z., Maruthappu, M., Gawn, L., Thompson, E. A., Athanasiou, T., \& Warren, O. J. (2012). Building effective clinical teams in healthcare. Journal of Health Organization and Management, 26(4), 428-436.

Farh, C. I., Seo, M-G. \& Tesluk, P. E. (2012). Emotional intelligence, teamwork effectiveness, and job performance: the moderating role of job context. Journal of Applied Psychology, 97(4), 890-900.

Finn, R., Currie, G., \& Martin, G. (2010). Team work in context: institutional mediation in the public-service professional bureaucracy. Organization Studies, 31(8), 10691097.

Fornell, C., \& Larcker, D. F. (1981). Structural equation models with unobservable variables and measurement error: Algebra and statistics. Journal of marketing research, 382-388.

Fornell, C., \& Bookstein, F. L. (1982). Two structural equation models: LISREL and PLS applied to consumer exit-voice theory. Journal of Marketing research, 440-452. 
Gardner, L., \& Stough, C. (2002). Examining the relationship between leadership and emotional intelligence in senior level managers. Leadership \& Organization Development Journal, 23(2), 68-78.

Ghuman, U. (2016). An empirical examination of group emotional intelligence in public sector workgroups. Team Performance Management, 22(1/2), 51-74.

Hair Jr., J. F., Anderson, R. E., Tatham, R. L., \& Black, W. C. (1998). Multivariate data analysis (5th ed). Upper Saddle River, NJ: Prentice-Hall.

Heckemann, B., Schols, J. M., \& Halfens, R. J. (2015). A reflective framework to foster emotionally intelligent leadership in nursing. Journal of Nursing Management, 23(6), 744-753.

Henseler, J. Fassott, G. (2009). “Testing Moderating Effects in PLS Path Models: An Illustration of Available Procedures," in Handbook of Partial Least Squares: Concepts, Methods and Applications in Marketing and Related Fields, Vincenzo Esposito Vinzi, Wynne W. Chin, Jörg Henseler, and Huiwen Wang, eds., Berlin: Springer, 713-735.

Hong, Y., Catano, V. M., \& Liao, H. (2011). Leader emergence: The role of emotional intelligence and motivation to lead. Leadership \& Organization Development Journal, 32(4), 320-343.

Huang, C. F. (2013). Shared leadership and team learning: Roles of knowledge sharing and team characteristics. Journal of International Management Studies, 8 (1), 124-133.

Imran, N., Aftab, M. A., Haider, I. I., \& Farhat, A. (2013). Educating tomorrow's doctors: A cross sectional survey of emotional intelligence and empathy in medical students of Lahore. Pakistan Journal of Medical Sciences, 29(3), 710- 714.

Jayasingam, S., Ansari, M. A., Ramayah, T., \& Jantan, M. (2013). Knowledge management practices and performance: are they truly linked?. Knowledge Management Research \& Practice, 11(3), 255-264.

Klare, D., Behney, M., \& Kenney, B. F. (2014). Emotional intelligence in a stupid world. Library Hi Tech News, 31(6), 21-24. 
Körner, M., Göritz, A. S., \& Bengel, J. (2014). Healthcare professionals' evaluation of interprofessional teamwork and job satisfaction/Evaluation der Teamarbeit und der Arbeitszufriedenheit von Gesundheitsfachberufen. International Journal of Health Professions, 1(1), 5-12.

Lazovic, S. (2012). The Role and Importance of Emotional Intelligence in Knowledge Management. In Knowledge and Learning: Global Empowerment; Proceedings of the Management, Knowledge and Learning International Conference 2012 (pp. 797805). International School for Social and Business Studies, Celje, Slovenia.

Xiao-Yu, L \& Liu, J. (2013). Effects of team leader emotional intelligence and team emotional climate on team member job satisfaction: A cross-level. Nankai Business Review International, 4(3), 180-198.

Lunenburg, F. C. (2011). Emotional intelligence in the workplace: Application to leadership. International Journal of Management, Business, and Administration, 14(1), 1-6.

Moriarty, P., \& Buckley, F. (2003). Increasing team emotional intelligence through process. Journal of European Industrial Training, 27(2/3/4), 98-110.

Berlin, J. M. (2014). Common incentives for teamwork-the unspoken contract's significance. Team Performance Management, 20(1/2), 65-80.

Mesmer-Magnus, J. R., \& DeChurch, L. A. (2009). Information sharing and team performance: a meta-analysis. Journal of Applied Psychology, 94(2), 535

Naeem, H., Saif, M. I., \& Khalil, W. (2011). Emotional Intelligence And Its Impact On Service Quality Empirical Evidence From The Pakistani Banking Sector. International Business \& Economics Research Journal (IBER), 7(12).

O'Leary, K. J., Sehgal, N. L., Terrell, G., \& Williams, M. V. (2012). Interdisciplinary teamwork in hospitals: a review and practical recommendations for improvement. Journal of Hospital Medicine, 7(1), 48-54. 
Pangil, F., \& Chan, J. M. (2014). The mediating effect of knowledge sharing on the relationship between trust and virtual team effectiveness. Journal of Knowledge Management, 18(1), 92-106.

Plowman, N. \& McDonough, M. (2010). Seven Factors of Effective Team Performance. Retriewed 5 August, 2011, from http://www.brighthub.com/office/projectmanagement/articles/62415.aspx.

RaesIi, I., Honarvar, M. S., Fallah, M. F., \& Behnood, V. (2016). The Relationship between Different Leadership Styles and Emotional Intelligence (EI) in Managers of Educational Groups (Case Study: Tehran Schools). International Journal of Humanities and Cultural Studies (IJHCS) ISSN 2356-5926, 514-527.

Rafaeli, A., \& Worline, M. (2001). Individual emotion in work organizations. Social Science Information, 40(1), 95-123.

Rahim, S. H. (2010). Emotional intelligence and stress: An analytical study of Pakistan banks. International Journal of Trade, Economics and Finance, 1(2), 194-199.

Reeves, S., Lewin, S., Espin, S., \& Zwarenstein, M. (2011). Interprofessional teamwork for health and social care (Vol. 8). John Wiley \& Sons.

Roldán, J. L., \& Sánchez-Franco, M. J. (2012). Variance-Based Structural Equation Modeling: Guidelines for Using Partial Least Squares in Information Systems Research. In M. Mora, O. Gelman, A. Steenkamp, \& M. Raisinghani (Eds.), Research Methodologies, Innovations and Philosophies in Software Systems Engineering and Information Systems (pp. 193-221). Hershey, PA: IGI Global

Schein, E. H. (1992). Organizational culture and leadership (2nd ed.). San Francisco: Jossey-Bass.

Shetach, A., \& Marcus, O. (2015). Citizenship-behavior, cooperation and job satisfaction of medical and nursing teams in an Israeli hospital. Team Performance Management: An International Journal, 21(3/4), 181-198. 
Sonenshein, S. (2014). How organizations foster the creative use of resources. Academy of Management Journal, 57(3), 814-848.

Steinheider, B., Bayerl, P. S., Menold, N., \& Bromme, R. (2009). Entwicklung und Validierung einer Skala zur Erfassung von Wissensintegrationsproblemen in interdisziplinären Projektteams (WIP). Zeitschrift für Arbeits-und Organisationspsychologie A\&O, 53(3), 121-130.

Shortell, S. M., Rousseau, D. M., Gillies, R. R., Devers, K. J., \& Simons, T. L. (1991). Organizational assessment in intensive care units (ICUs): construct development, reliability, and validity of the ICU nurse-physician questionnaire. Medical care, 709-726.

Thylefors, I. E. C., \& Persson, O. (2014). The more, the better? Exploring vertical and horizontal leadership in cross-professional health care teams. Leadership in Health Services, 27(2), 135-149.

Weller, J., Boyd, M., \& Cumin, D. (2014). Teams, tribes and patient safety: overcoming barriers to effective teamwork in healthcare. Postgraduate medical journal, 90(1061), 149-154.

Wong, C. S., \& Law, K. S. (2002). The effects of leader and follower emotional intelligence on performance and attitude: An exploratory study. The Leadership Quarterly, 13(3), 243-274.

Udod, S. A., \& Care, W. D. (2013). 'Walking a tight rope': an investigation of nurse managers' work stressors and coping experiences. Journal of Research in Nursing, 18(1), 67-79.

Xiao, Y., Parker, S. H., \& Manser, T. (2013). Teamwork and collaboration. Reviews of Human Factors and Ergonomics, 8(1), 55-102. 